\title{
RESISTÊNCIA AO CISALHAMENTO E GRAU DE INTEMPERISMO DE CINCO SOLOS NA REGIÃO DE LAVRAS (MG) ${ }^{(\mathbf{1})}$
}

\author{
W. W. ROCHA ${ }^{(2)}$, M. S. DIAS J UNIOR ${ }^{(3)}$, J . M. LIMA(3), \\ E. E. V. MIRANDA(4) \& A. R. SILVA(4)
}

\begin{abstract}
RESUMO
Atualmente os parâmetros da resistência ao cisalhamento dos solos podem ser uma ferramenta muito útil na estabilização de taludes e recuperação de voçorocas, bem como na adoção de práticas mecânicas de conservação para os solos agrícolas. Com o objetivo de avaliar a resistência ao cisal hamento de cinco solos da região de Lavras (MG) e sua relação com o grau de intemperismo, realizou-se um experimento, utilizando uma prensa de cisalhamento direto, a qual permite ensaiar amostras indeformadas de solos. Essas amostras foram coletadas na profundidade de 0-0,03 m e submetidas ao ensaio de cisal hamento, para a definição das envoltórias de resistência e obtenção da coesão aparente (c) e o ângulo de atrito interno ( $\phi$ ). Observou-se que c, de forma geral, foi maior para solos que apresentaram maior densidade, umidade a $-0,01 \mathrm{MPa}$ e maior teor de areia. Os valores de $(\phi)$ foram maiores nos solos com maiores teores de argila. O Latossolo Vermel ho-Amarelo distrófico (LVAd) e o Argissolo VermelhoAmarelo distrófico típico (PVAd), com densidades do solo, teores de areia e umidade a -0,01MPa mai ores, apresentaram maiores resistências ao cisalhamento em relação ao Latossolo Vermelho distrófico (LVd), Cambissolo Háplico Tb distrófico (CXbd) e Latossolo Vermelho distroférrico (LVdf), que apresentaram maiores teores de argila e matéria orgânica. Para a classe dos Latossolos, a resistência ao ci salhamento foi maior onde os índices Ki e Kr foram mais elevados, graças à estrutura em blocos apresentada pelo LVAd, que condicionou maior resistência ao cisalhamento. Do ponto de vista da resistência ao cisalhamento, os solos LVAd e PVAd mostraram-se mais resistentes a voçorocamento e ao preparo do solo.
\end{abstract}

Termos para indexação: conservação do solo, estrutura, textura, densidade do solo, erosão.

(1) Recebido para publicação em fevereiro de 2001 e aprovado em fevereiro de 2002.

(2) Doutorando no Departamento de Ciência do Solo, Universidade Federal de Lavras - UFLA. Caixa Postal 37, CEP 37200-000 Lavras (MG). Bolsista do CNPq. E-mail: www@ufla.br

(3) Professor Adjunto IV/DCS, UFLA. Bolsista do CNPq. E-mails: msousadj@ufla.br; jmlima@ufla.br

(4) Mestrando no Departamento de Ciência do Solo, UFLA. 


\title{
SUMMARY: SHEAR STRENGTH AND WEATHERING RATE OF FIVE SOILS IN THE REGION OF LAVRAS, MINAS GERAIS STATE, BRAZIL
}

\begin{abstract}
Knowledge on soil shear strength can actually be a very useful tool for the control of slopeand gully erosion, as well as for theintroduction of mechanical conservation practices in agricultural soils. In order to evaluate the shear strength of five soils in the region of Lavras (MG) and its relation with the weathering rate, an experiment was carried out, using a direct shear machinewhich allows thecollection of undisturbed soil samples. These samples were coll lected at a depth between 0 and $0.03 \mathrm{~m}$ and subjected to theshear strength treatment for the definition of rupture lineand the obtainment of the apparent cohesion (c) and the internal friction angle $(\phi)$. In general, c was higher in soils which presented a higher density, humidity/ moisture at $-0.01 \mathrm{MPa}$ and a higher sand content. The $(\phi)$ values were higher in soils with higher clay contents. The distrophic Red-Yellow Latosol (dRYL) and the typical distrophic Red-Yellow Utisol (tdRYU) with greater soil densities, sand contents and moisture at $-0.01 \mathrm{MPa}$, presented higher shear strength than the distrophic Red Latosol (dRL), distrophic Inceptsoil (dl) and distroferric Red Latosol (dRL), which contained higher contents of clay and organic matter. For Latosols, thesoil shear strength was higher where $\mathrm{Ki}$ and $\mathrm{Kr}$ indices increased, due to the block structure of the $\mathrm{dRYL}$, causing el evated shear strength. In relation to shear strength, the dRYL and the tdRYU proved to bemore resistant to gully erosion and tillage practices.
\end{abstract}

Index terms: soil conservation, structure, texture, bulk density, erosion.

\section{NTRODUÇÃO}

A carência de informações sobre os parâmetros de resistência ao cisal hamento dos sol os agrícolas e suas relações com as demais propriedades dos solos têm limitado o desenvol vimento detécnicas quevisem à estabilidade de taludes deterra, princi palmente no caso de voçorocas. Durante o processo de evolução das voçorocas, seus taludes podem sofrer ruptura mecânica, segundo uma superfície de falhamento. Esta superfície apresenta, em todos os seus pontos, tensão de cisal hamento no limite da resistência ao cisal hamento (Vargas, 1989). Na agricultura, o estudo da resistência ao cisal hamento pode auxiliar na determinação da capacidade de suporte de carga dos solos e, conseqüentemente, na especificação do maquinário e implemento mais adequado ao sistema de manejo (Ohu et al., 1986).

A resistência ao cisal hamento dos solos pode ser expressa pela equação de Coulomb, $\tau=c+\sigma_{\mathrm{n}} \operatorname{tg} \phi$ (Vargas, 1989), em que $\tau$ é a máxima pressão cisal hante suportada pelo solo, $\sigma_{\mathrm{n}}$ éa tensão normal a que a superfície de fal hamento está submetida, cé o intercepto de coesão ou coesão aparente do sol o e $\phi$ é o ângulo de atrito interno do solo, definido como sendo o ângulo que a força normal faz com a resultante das forças que o maciço terroso está submetido. Esta equação define a envoltória de resistência, que é a linha-limite de resistência dos solos, ou seja, qualquer força cisalhante que esteja acima desta linha promoverá a ruptura do solo. Os parâmetros c e $\phi$ são características intrínsecas dos solos (Benjamim \& Cruse ,1985), e se $\sigma_{\mathrm{n}}$ for nulo, a expressão $\sigma_{\mathrm{n}}$ tg $\phi$ será nula e a resistência ao cisalhamento do solo será dependente apenas do intercepto de coesão.

Pelo fato deas partículas de areia, principal mente as de menor tamanho, quando submetidas a forças externas, ocuparem mais facilmente os espaços vazios do solo, aumentando, assim, a área de contato entre agregados e, solos com maiores quantidades de areia, onde as partículas não apresentem uma distribuição uniforme quanto ao tamanho, tendem a apresentar maior resistência ao cisal hamento, (Ortigão, 1995). No caso de sol os argil osos, o estudo da resistência ao cisalhamento torna-se mais compl exo, pel ofato de ser a argila a fração mais ativa do solo, e os processos físicos e químicos, tais como: sucessivas arações e gradagem, flutuação do lençol freático através de drenagens, adubações fosfatadas e calagem, que atuam no sentido de aumentar ou reduzir o contato entre partículas do solo, conseqüentemente, aumentarão ou reduzirão a resistência ao cisalhamento (Terzaghi et al., 1997).

A resistência ao cisalhamento do solo pode também ser usada como um indicador decompactação do sol o (Ayers \& Perumpral, 1982; Schjonning, 1991). Em geral, os solos mais compactados apresentam mai or resistência ao cisal hamento (Azevedo, 1999), mediante a menor distância entre as partículas, o que Ihes confere, conseqüentemente, menor índice de vazios e requer maior esforço para prepará-los para o cultivo.

A umidade e o teor de matéria orgânica podem influenciar a resistência ao cisal hamento do solo, de 
forma que, em sol os com baixos val ores de umidade, a matéria orgânica tende a reduzir a resistência ao cisal hamento, dependendo da menor densidade do sol oconferida por ela (E kwue\& Stone, 1995). Assim, a resistência ao cisalhamento dos solos é uma variável importante na caracterização das alterações estruturais do solo (Cruse \& Larson, 1977; Davies, 1985; Gantzer et al., 1987).

Os objetivos deste trabalho foram: (a) avaliar a resistência ao cisal hamento de cinco classes de sol os da região de Lavras (MG), (b) relacionar estas informações com o grau de intemperismo desses sol os.

\section{MATERIAL E MÉTODOS}

Este estudo foi desenvolvido em amostras das seguintes classes de solos: Latossolo Vermel hoAmarelo distrófico (LVAd) A moderado textura argilosa fase floresta tropical subcaducifólia relevo suave ondulado; Latossol oVermel ho distrófico (LVd) A moderado textura argilosa fase cerrado relevo suave ondulado; Latossolo Vermel ho distroférrico (LVdf) textura argilosa fase floresta tropical subperenefólia relevo suave ondulado; Argissolo Vermel ho-Amarelo distrófico típico (PVAd) A moderado textura média/argilosa fase floresta tropical subcaducifólia rel evo ondulado e Cambissolo HáplicoTb distróficotípico (CXbd)A moderadotextura média fase floresta subcaducifólia relevo forte ondulado, todos localizados na região de Lavras (MG). Utilizou-se, no ensaio de cisal hamento direto, uma prensa de cisalhamento fabricada pela ELE International (Digital Shear Machine, 26-112 - 9901X0089) (Figura 1). O equi pamento operou com vel ocidade de deslocamento horizontal de $3,33 \times 10^{-5} \mathrm{~m} \mathrm{~s}^{-1}$ etensões normais de 28, 42, 55 e $69 \mathrm{kPa}$.

As amostras foram coletadas com estrutura indeformada na profundidade de 0-0,03 m, em amostradores quadrados especialmente desenvolvidos para este fim, com 0,0595 m de largura e

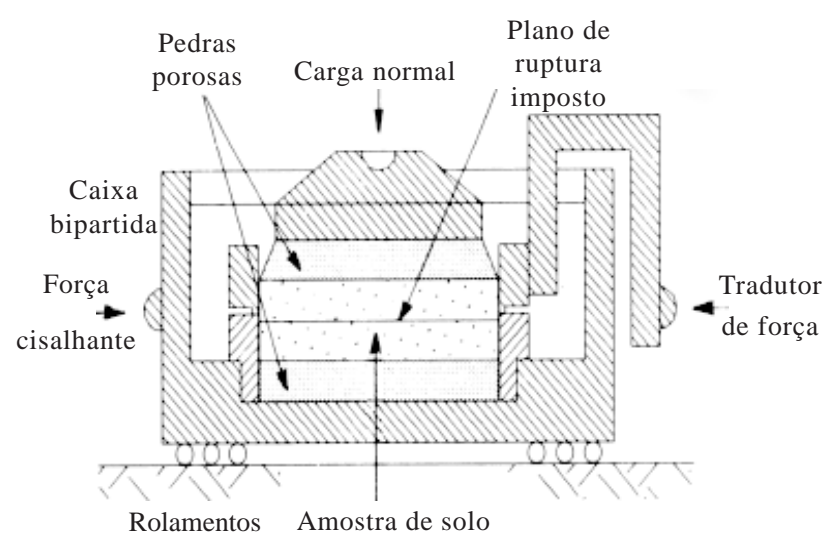

Figura 1. Caixa de cisalhamento utilizada em ensaios de cisalhamento direto. comprimento e 0,022 m de altura. Foram col etadas 16 amostras para cada classe de solo, sendo quatro repetições para quatro diferentes cargas verticais, somando um total de oitenta amostras.

Todas as amostras de solo foram saturadas e equilibradas a uma tensão de 0,01 MPa. A calibração do equipamento consistiu em: calibração do anel dinamométrico e nivelamento horizontal do braço de alavanca onde são aplicadas as cargas verticais, com a finalidade de evitar possíveis variações angulares, quando da aplicação das cargas, para que se possa manter a relação de aplicação da carga normal de 1:10, ou seja, 1 kgf aplicado na máquina corresponde a $10 \mathrm{kgf}$ aplicados na amostra. A constante do anel dinamométricotambém foi aferida para diferentes cargas aplicadas, uma vez que este valor influi no cálculo e na correção da força horizontal aplicada na amostra de solo.

Após a determinação da tensão cisalhante máxima e da tensão normal aplicada, a envoltória de resistência foi traçada, obtendo-se o ângulo de atrito interno do solo e o intercepto de coesão, que representa a coesão aparente dos solos.

Na tentativa de verificar a relação da resistência ao cisalhamento dos solos com o seu grau de intemperismo, foram determinados os índices $\mathrm{Ki}$ e $\mathrm{Kr}$ por meio dos teores de óxidos do ataque sulfúrico (EMBRAPA, 1997).

Para estudar a relação entre as diferentes variáveis dos solos e suas respectivas resistências ao cisalhamento, uma vez que essa resistência é crescente com a aplicação da carga normal, calculousea resistência ao cisal hamento máxima de ensaio, substituindo o valor da máxima tensão normal aplicada na equação da envoltória de resistência obtida para cada solo.

As análises de regressões realizadas utilizaram o software Sigma Plot 4.0 (J andel Scientific), e as comparações das regressões foram feitas seguindo o procedimento descrito em Snedecor \& Cochran (1989).

\section{RESULTADOS E DISCUSSÃO}

No quadro 1, estãoapresentados os resultados dos ensaios de cisalhamento direto, assim como da densidade do solo, teores de argila eareia eumidade a -0,01 MPa das cinco classes de solos estudadas. Observa-se que a coesão aparente c decresceu na seguinte ordem: PVAd $>$ LVAd $>$ LVd $>$ CXbd $>$ LVdf. $J$ á os valores do ângulo de atrito interno $\phi$ foram decrescentes na ordem: LVdf $>$ LVAd $>$ CX bd $>$ PVAd $>$ LVd. Pode-se notar que, com exceção do LVdf, para todas as demais dasses de sol o, os val ores de c foram superiores aos valores de $\phi$; neste caso, c contribui de forma mais atuante na resistência ao cisalhamento. Por ser esta coesão aparente um dos componentes da resistência ao cisal hamento do sol o 
Quadro 1. Densidade do solo (Ds ), umidade na sucção de $0,01 \mathrm{MPa}$ (U), quantidades de argila e areia e resultados do ensaios de cisal hamento direto em amostras indeformadas coletadas na profundidade de 0 a $0,03 \mathrm{~m}$, para a umidade a $-0,01 \mathrm{MPa}$

\begin{tabular}{|c|c|c|c|c|c|c|c|}
\hline $\begin{array}{l}\text { Classe } \\
\text { de solo }\end{array}$ & Ds & Argila & Areia & Silte & $\begin{array}{l}\text { Umidade a } \\
-0,01 \mathrm{MPa}\end{array}$ & $\begin{array}{c}\text { Ângulo de atrito } \\
\text { interno }(\phi)\end{array}$ & $\begin{array}{c}\text { Coesão } \\
\text { aparente (c) }\end{array}$ \\
\hline & $\mathrm{kg} \mathrm{dm}^{-3}$ & 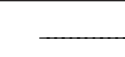 & $-\mathrm{g} \mathrm{kg}^{-1}$ & - & $\mathrm{kg} \mathrm{kg}^{-1}$ & o & $\mathrm{kPa}$ \\
\hline LVdf & 1,15 & 570 & 160 & 270 & 0,21 & 23,75 & 12,56 \\
\hline LVd & 1,12 & 570 & 250 & 180 & 0,22 & 6,30 & 38,39 \\
\hline LVAd & 1,31 & 310 & 460 & 230 & 0,29 & 11,30 & 40,68 \\
\hline PVAd & 1,29 & 370 & 390 & 240 & 0,28 & 7,80 & 42,39 \\
\hline CXbd & 1,19 & 396 & 150 & 460 & 0,25 & 8,97 & 33,39 \\
\hline
\end{tabular}

e ocorrer somente em sol os parcialmente saturados (Pinto, 1989), propriedades físicas e químicas que promovam al terações na interação água-soloinfluem nos valores de c (Terzaghi et al., 1997).

Os valores de $\phi$ variaram de 6,30 a $23,75^{\circ}$ e, de maneira geral, exceto para o LVdf, observou-se uma redução de $\phi$ com o aumento do teor de argila dos solos. Os valores de $\phi$, segundo Ortigão (1995), mostraram-se muito variáveis e dependentes da forma com a qual as partículas de areia e argila estavam distribuídas por tamanho e áreas de contato. Segundo esse autor, não se verificou correlação entre o valor de $\phi$ e as características físicas equími cas dos sol os. Pinto (1989), entretanto, observou que os valores de $\phi$ tendem a ser menores para maiores quantidades de argila dos solos.

Na figura 2, estão representadas as envoltórias de resistência das cinco classes de sol os estudadas. As envol tórias de resistência ao cisal hamento foram estatisticamente diferentes, mostrando quea tensão cisalhante é uma característica intrínseca de cada classe de solo.

A ordem decrescente de resistência ao cisal hamento dos sol os foi a seguinte: LVAd >PVAd > LVd $>$ CXbd $>$ LVdf. O LVAd e o PVAd apresentaram os maiores valores de tensões cisalhantes e, conseqüentemente, maior resistência ao cisal hamento. Tal comportamento pode ser explicado pela maior facilidade com que as partículas destes solos têm em ocupar os espaços vazios, quando submetidos a forças promotoras de deformações, causando com isto um maior atrito entre estas partículas. Esse atrito reflete na maior resistência ao cisalhamento observada, que também depende da estrutura em blocos desses solos, responsável pelo aumento na área de contato entre as partículas.

O LVdf e o LVd, embora apresentem maior porosidade total e, conseqüentemente, drenagem mais rápida, mostraram menor resistência ao cisal hamento do que o LVAd ePVAd, provavel mente, pela redução das tensões capilares. Outro aspecto

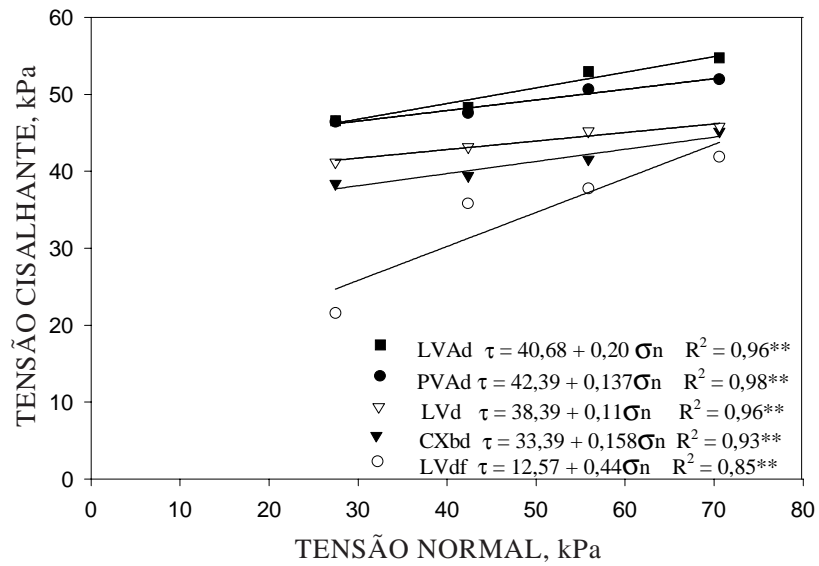

Figura 2. Envoltórias de resistência para os cinco solos estudados.

que confere menor resistência ao cisal hamento para - LVdf e LVd está ligado ao fato de esses solos apresentarem estrutura granular, nas quais as superfícies de contato entre as partículas e microagregados são reduzidas. O CXbd, entretanto, está entre os solos de menor resistência ao cisalhamento, em razão do menor grau de evolução genética, expresso pel o maior teor de silte desse sol o (Quadro 1), o que Ihe confere menor grau de estruturação de suas partículas.

Do ponto de vista de conservação do solo, esses resultados evidenciam que oLVAd eo PVAd são mais resistentes ao voçorocamento, por apresentarem maior resistência às forças cisalhantes e, conseqüentemente, ao processo de erosão. Deacordo com Silva (1990), estes sol os contêm menores teores deóxidos de ferro eestrutura em blocos, para oPVAd, e tendendo para blocos, para o LVAd, em alguns casos, com mai or coerência entre os agregados, o que ajuda a diminuir substancialmentea erosão. Esperase, entretanto, que o LVAd e o PVAd apresentem 
também maior resistência mecânica ao preparo, o queacarretará mai or potência requerida pelo trator, maior consumo decombustível e maior desgaste dos implementos, com redução significativa de sua vida útil.

O LVd e o LVdf apresentam em sua estrutura grânulos em formas aproximadas de esferas, com reduzida área de contato entre elas, o que, aliado com seu pequeno tamanho, torna-os facilmente deslocáveis pela água (Silva, 1990). A razão de os solos LVdf e LVd serem menos propensos ao voçorocamento natural, embora apresentem menor resistência ao cisalhamento, está relacionada com sua alta permeabilidade, com um "sólum" mais profundo e, ainda, com as áreas de relevo plano e suave ondulado (Silva et al., 1993) desses solos, o que minimiza a energia cisalhante da água.

Os maiores teores de silte (Quadro 1), a pouca espessura do "sólum", a baixa permeabilidade, a pobreza química acentuada e o relevo mais movimentado tornam o CXbd muito instável (Curi et al., 1990). Nesse solo, a energia cisalhante da enxurrada é mais acentuada, causando, além da erosão laminar, o surgimento de voçorocas.

Assim, espera-se que solos com estrutura em blocos sejam mais resistentes à erosão em sulcos e ao preparo. Portanto, a determinação da resistência ao cisal hamento dos sol os pode ser uma ferramenta útil a ser considerada no estabel ecimento desistemas de preparo de sol o e do manejo conservacionista.

Na figura 3, observa-seque, para diferentes dasses de solos, a resistência ao cisalhamento aumentou com o aumento da densidade do solo. Os sol os compactados ou mais adensados tendem a apresentar maior resistência ao cisalhamento (Azevedo, 1999), em conseqüência do maior contato entre as suas partículas, conferindo-lhes maior atrito (Terzaghi et al., 1997), conforme revelam o LVAd e PVAd.

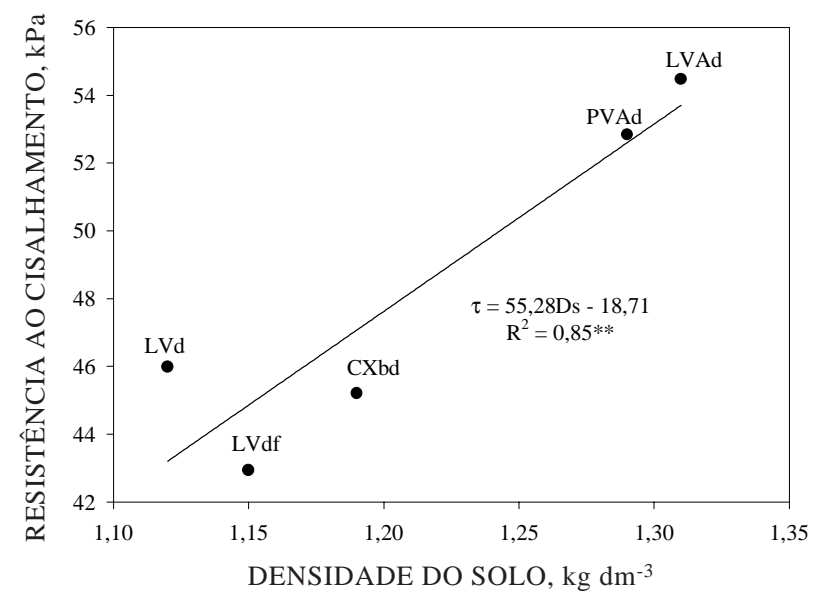

Figura 3. Variação da resistência ao cisalhamento dos solos com a densidade do solo.
A relação entre resistência ao cisalhamento dos sol os e a sua umidade correspondente à tensão de 0,01 MPa está apresentada na figura 4. Observase, para as diferentes dasses de sol os, que, à medida que a umidade correspondente a -0,01 $\mathrm{MPa}$ aumentou, a resistência ao cisal hamento também aumentou. Isto podeser devido às maiores densidades apresentadas por estes solos (Figura 3) e a um aumento das tensões capilares o que confere maior estabilidade à estrutura dos sol os (Azevedo, 1999).

Plotando resistência ao cisal hamento em função do teor de areia dos solos (Figura 5), observa-se um aumento da resistência ao cisalhamento com o aumento do teor deareia. I stoé devido à capacidade deas partículas de areia se rearranjarem demaneira mais densa (Dias J unior \& Miranda, 2000), provocando maior densidade do solo (Figura 3), maior atrito e, conseqüentemente, mai or resistência ao cisal hamento. Os solos LVd, CXbd e LVdf, com maiores teores de argila (Figura 6), apresentaram menor densidade do solo, menor umidadea 0,01 MPa (Quadro 1) e menor resistência ao cisal hamento. O fato de a argila proporcionar menor resistência ao cisalhamento está também relacionado com a mineralogia do solo (Terzaghi et al., 1997), que, de certa forma, éinfluenciada pela adsorção/dessorção de íons que podem promover a dispersão do solo. Segundo Silva et al. (1993), nos solos LVd e LVdf, predomina a gibbsita e, nos solos PVAd, LVAd e CXbd, predomina, dentre outras, a caulinita.

$\mathrm{Na}$ figura 7, embora sejam classes de solos diferentes, observou-se, em concordância com Ohu et al. (1986), que os solos com maiores teores de matéria orgânica (Quadro2) apresentaram também menores densidades do solo (Quadro 1), reduzindo o contato entre as partículas, o que acarretou menor resistência ao cisal hamento. U ma vez quea maioria dos sol os agrícolas são cultivados com baixos teores

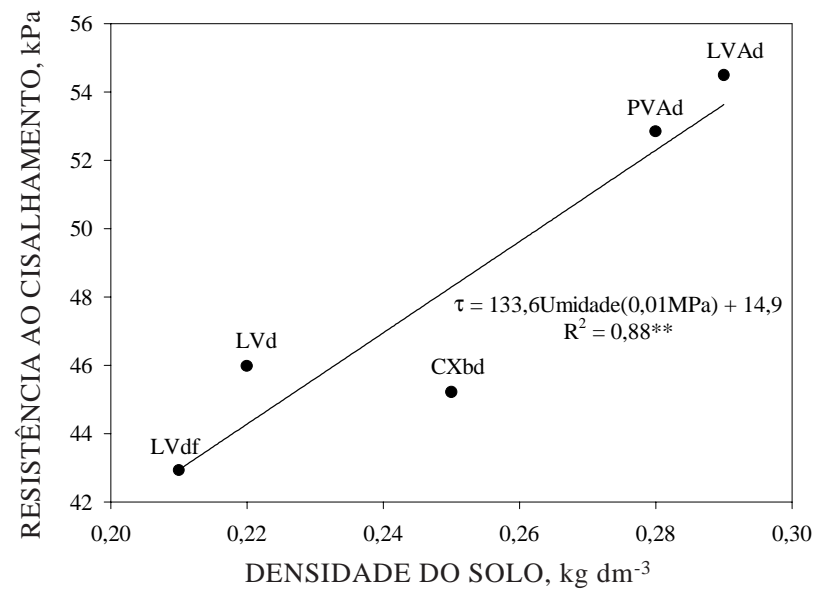

Figura 4. Variação da resistência ao cisalhamento dos solos com a umidade dos solos. 


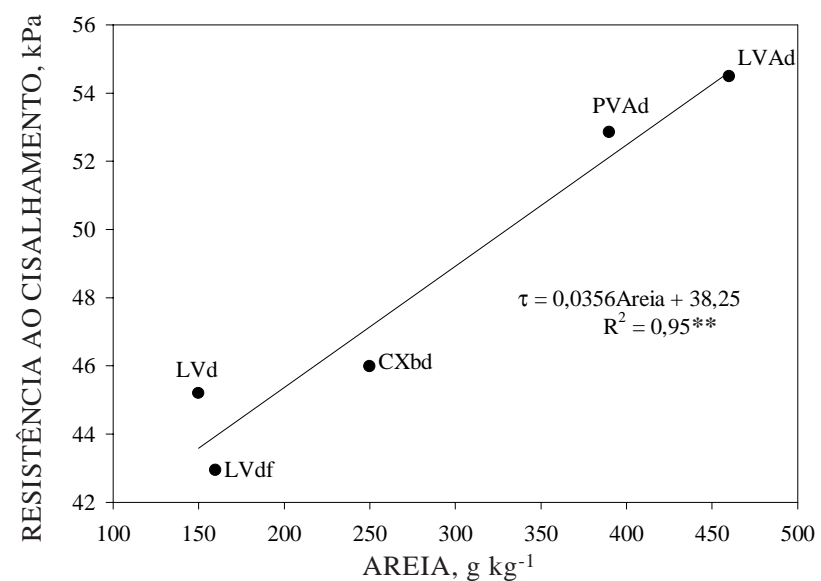

Figura 5. Variação da resistência ao cisalhamento dos solos com o teor de areia.

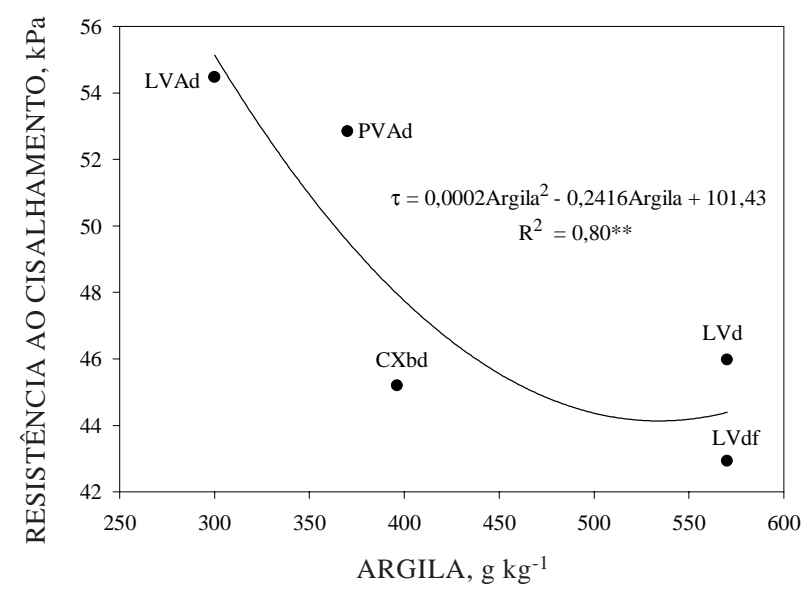

Figura 6. Variação da resistência ao cisalhamento dos solos com o teor de argila.

de matéria orgânica (Ekwue \& Stone, 1995), a variação da resistência ao cisal hamento do sol o com os teores de matéria orgânica deve ser mais bem estudada, pois pode permitir a correta especificação do equipamento a ser utilizado no preparo do solo.

As figuras 8 e 9 relacionam a resistência ao cisal hamento dos sol os estudados com os índices de intemperismo Ki e Kr, (Quadro 2). Observa-se que, para uma condição de sol o mais jovem, como éo caso do CXbd, a resistência ao cisalhamento dos solos é baixa.

Sol os em estado mais jovem de desenvol vimento, como o CXbd, que apresentam maiores valores de $\mathrm{Ki}$ e Kr (Quadro 2) e maiores teores de silte (Quadro 1), podem apresentar menor grau de estruturação, com conseqüente redução do contato entre as partículas e menores forças de atrito atuantes sobre este solo. J á para o PVAd, sol o com horizonte $\mathrm{B}$ textural, por dispor de uma estrutura em blocos, de forma geral, pode apresentar maior
Quadro 2. Matéria orgânica, Ki e Kr, dos cinco solos estudados

\begin{tabular}{lccc}
\hline $\begin{array}{c}\text { Classe } \\
\text { de solo }\end{array}$ & $\begin{array}{c}\text { Matéria } \\
\text { orgânica }\end{array}$ & $\mathbf{K i}$ & $\mathbf{K r}$ \\
\hline & $\mathrm{g} \mathrm{kg}^{-1}$ & & \\
LVdf & 18,6 & 0,89 & 0,58 \\
LVd & 21 & 0,91 & 0,71 \\
LVAd & 8,8 & 1,02 & 0,92 \\
PVAd & 9,5 & 1,52 & 1,28 \\
CXbd & 21,8 & 1,60 & 1,43 \\
\hline
\end{tabular}

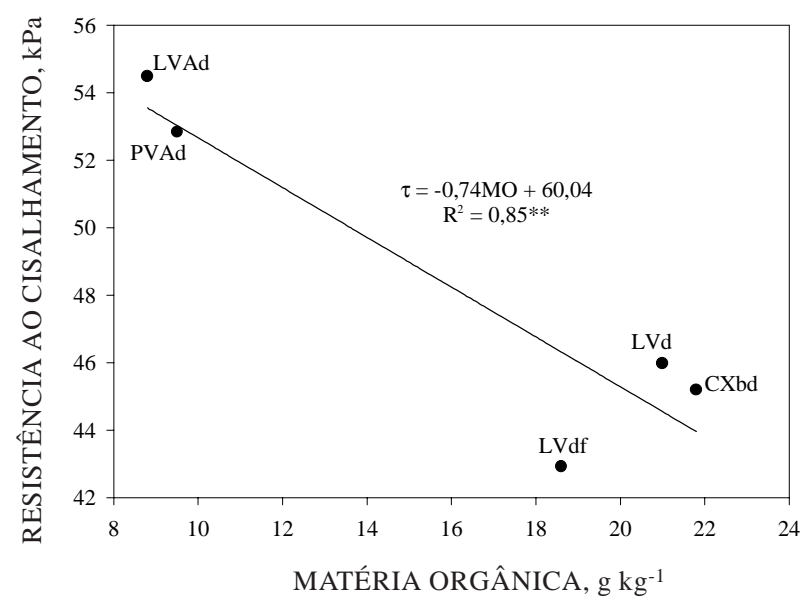

Figura 7. Variação da resistência ao cisalhamento do solo com o teor matéria orgânica.

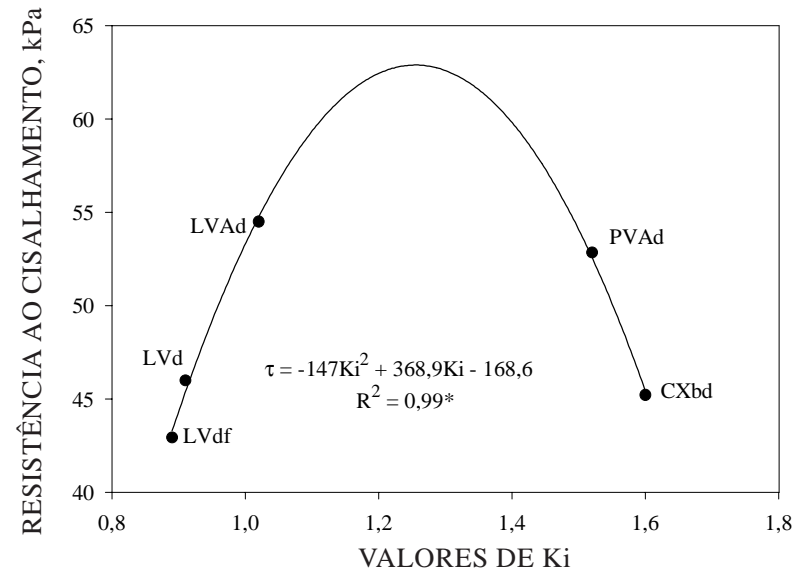

Figura 8. Variação da resistência ao cisalhamento dos solos com o índice Ki.

contato entre as partículas, o que lhe confere maior resistência ao cisalhamento.

Nos Latossolos, solos mais intemperizados, observa-se que, à medida em que há redução de Ki e $\mathrm{K} r$, há também redução nos valores de resistência 


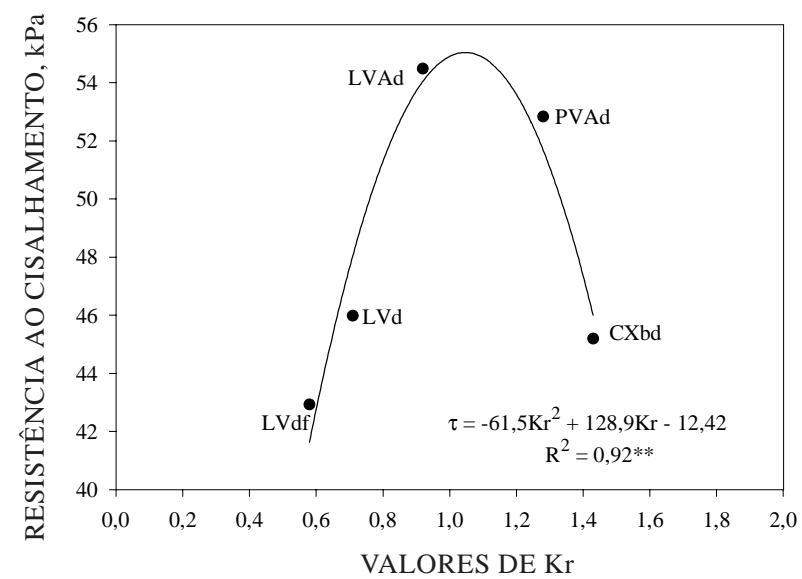

Figura 9. Variação da resistência ao cisalhamento dos solos com o índice $\mathrm{Kr}$.

ao cisal hamento, na seqüência LVAd $>$ LVd $>$ LVdf. $\mathrm{O}$ desenvolvimento da estrutura granular, do LVd para o LVdf, condiciona o menor atrito entre as partículas, conferindo menor resistência ao cisalhamento.

\section{CONCLUSÕES}

1. Os sol os LVAd ePVAd, com densidades do solo, quantidades de areia eumidadea -0,01MPa maiores, apresentaram maior resistência ao cisal hamento em relação ao $L V d, C X b d$ e $L V d f$, que apresentaram maiores teores de argila e de matéria orgânica.

2. A coesão aparente, de forma geral, foi maior para sol os com mai ores: densidade do sol o, umidade a -0,01 MPa e teor de areia.

3. Para a classe dos Latossolos, a resistência ao cisalhamento diminuiu com a redução dos índices $\mathrm{Ki}$ e Kr.

4. A estrutura em blocos condiciona maior resistência ao cisal hamento aos solos.

\section{LITE RATURA CITADA}

AYERS, P.D. \& PERUMPRAL, J.V. Moisture and density effect on cone index.Trans. Am. Sci. Agric. Eng., 21:1169-1172, 1982.

AZE VEDO, M.A.A. Contribuição ao estudo geotécnico de solos de Viçosa - MG. Viçosa, MG, Universidade Federal de Viçosa, 1999. 169p. (Tese de Mestrado)

BENJ AMIN, J .G. \& CRUSE, R.M. Mesurement of shear strength and bulk density of soil aggregates. Soil. Sci. Soc. Am. J., 49:1248-1251, 1985.
BENJ AMIN, J.G. \& CRUSE, R.M. Tillage effects on shear strength and bulk density of soil aggregates. Soil Till. Res., 9:255-263, 1986

CURI, N.; LIMA, J.M.; ANDRADE, H. \& GUALBERTO, V. Geomorfol ogia, física, química e mineralogia dos principais solos da região de Lavras, MG. Ci. Prat., 14:297-307, 1990.

CRUSE, R.M. \& LARSON, W.E. Effects of soil shear strength on soil detachment due to rain drop impact. Soil Sci. Soc. Am. J., 41:777-781, 1977.

DIAS J ÚNIOR, M.S. \& MIRANDA, E.E.V. Comportamento da curva de compactação de cinco solos da região de Lavras MG. Ci. Agrotec., 24:337-346, 2000.

DAVIES, P. Influence of organic matter, moisture status and time after reworking on soil shear strength. Soil Sci. Soc. Am. J., 36:299-306, 1985.

EKWUE, E.J . \& STONE, R.J . Organic matter effects on the strength properties of impacted agricultural soils. Trans. Am. Sci. Agric. Eng., 38:357-365, 1995.

EMPRESA BRASILEIRA DE PESQUISA AGROPECUÁRIA EMBRAPA. Centro Nacional de Pesquisa de Solos. Manual de métodos de análises de solo. 2.ed. Rio de J aneiro, 1997. 212p.

GANTZER, C.J .; BUYANOVSKY, G.A.;ALBERTS, E. \& REMLEY, P.A. Effects of soybean and crop residue deposition on soil strength and splash detachment. Soil Sci. Soc. Am. J., 51:202-206, 1987.

OHU, O.J.; RAGHAVAN, G.S.V.; MCKYES, E. \& MEHUYS, G. Shear strength prediction of soils with varying added organic matter contents. Trans. Am. Sci. Agric. Eng., 29:351-355, 1986.

ORTIGÃO, J .A.R. I Introdução à mecânica dos solos dos estados críticos. 2.ed. Rio deJ aneiro, Livros Técnicos e Científicos, 1995. v.1. 374p

PINTO, C.S. Resistência ao cisal hamento dos solos. São Carlos. Grêmio Politécnico, 1989. v.1. 127p

SCHJ ONNING, P. Shear strength determination in undisturbed soil at controlled Water Potential. Soil Till. Res., 8:171179, 1986

SCHJ ONNING, P. Soil strength as influenced by texture, water content and soil management. Soil Till. Res., 12:277-283, 1991.

SI LVA, A.C. Relação entre voçorocas e sol os na região de LavrasMG. Lavras, Escola Superior de Agricultura de Lavras, 1990.124p. (Tese de Mestrado)

SILVA, A.C.; LI MA, J .M. \& CURI, N. Relações entre voçorocas, uso da terra, sol o e materiais de origem da região de Lavras (MG). R. Bras. Ci. Solo, 17:459-464,1993.

SNEDECOR, G.W. \& COCHRAN, W.G. Statistical methods. 8.ed. Aimes : I owa State University, 1989. 161p.

TERZAGHI, K.; PECK, R.B. \& MESRI, G. Soil mechanics in engineering pratice. 3.ed.New York, J ohn Wiley \& Sons, 1997. 549p.

VARGAS, M. Introdução à mecânica dos solos. São Paulo, McGraw-Hill,1989. 509p. 
W.W. ROCHA et al.

R. Bras. Ci. Solo, 26:297-303, 2002 